\title{
Utilization of potentially inappropriate medication and risk of adverse drug events among older adults with chronic renal insufficiency: a population-wide cohort study
}

Safoura Sheikh Rezaei ${ }^{1}$, Hana Šinkovec ${ }^{2^{*}}$ (D), Alexander Schöberl ${ }^{3}$, Christoph Rinner ${ }^{3}$, Georg Heinze ${ }^{2}$, Michael Wolzt ${ }^{1}$ and Walter Gall ${ }^{3}$

\begin{abstract}
Background: The use of potentially inappropriate medication (PIM) in population of older adults may result in adverse drug events (ADE) already after short term exposure, especially when it is prescribed to patients with chronic kidney disease (CKD). In order to limit ADE in the treatment of older adults PIM lists have been constructed as a source of information for healthcare professionals. The aim of this study was to estimate the utilization of PIM and incidence of ADE in older adults ( $\geq 70$ years) with CKD.

Methods: We conducted a retrospective population-wide cohort study including patients from Lower Austria who were 70 years or older and diagnosed with CKD in the period from 2008 to 2011. Utilization of PIM was estimated from prescriptions filled by target population. We estimated risks of hospitalization due to ADE within 30 days after incident PIM prescription and compared them to a PIM-free control group by using marginal structural models (MSM).

Results: We identified 11,547 patients (women: 50.6\%, median age in 2008: 78 years) who fulfilled the inclusion criteria. In total 24.7 and $8.1 \%$ of all prescriptions from that period contained a medication with a substance listed in the EU (7)-PIM and AT-PIM list, respectively. Proton pump inhibitors and Ginkgo biloba were the most often prescribed PIMs in this population. 94.6 and 79.3\% patients filled at least one EU(7)-PIM and AT-PIM prescription, respectively. Despite the relatively high utilization of PIM there was only a low incidence of clinically relevant ADE. No event type exceeded the threshold level of $1 \%$ in the analysis of risks of ADE after filling a prescription for PIM. Nevertheless, MSM analysis showed an increased risk for 11 drugs and reduced risk for 4 drugs.

(Continued on next page)
\end{abstract}

\footnotetext{
* Correspondence: hana.sinkovec@meduniwien.ac.at

${ }^{2}$ Section for Clinical Biometrics, Center for Medical Statistics, Informatics and Intelligent Systems, Medical University of Vienna, Spitalgasse 23, 1090 Vienna, Austria

Full list of author information is available at the end of the article
}

(c) The Author(s). 2021 Open Access This article is licensed under a Creative Commons Attribution 4.0 International License, which permits use, sharing, adaptation, distribution and reproduction in any medium or format, as long as you give appropriate credit to the original author(s) and the source, provide a link to the Creative Commons licence, and indicate if changes were made. The images or other third party material in this article are included in the article's Creative Commons licence, unless indicated otherwise in a credit line to the material. If material is not included in the article's Creative Commons licence and your intended use is not permitted by statutory regulation or exceeds the permitted use, you will need to obtain permission directly from the copyright holder. To view a copy of this licence, visit http://creativecommons.org/licenses/by/4.0/ The Creative Commons Public Domain Dedication waiver (http://creativecommons.org/publicdomain/zero/1.0/) applies to the data made available in this article, unless otherwise stated in a credit line to the data. 
(Continued from previous page)

Conclusions: PIM prescription was common among older adults with CKD, however, only a small number of these drugs eventually led to hospitalization due to ADE within 30 days after incident PIM was filled. In the absence of a clinically important PIM-related increase in risk, an assessment of potential ADE severity to a PIM list by using a warning score system seems prudent.

Keywords: Medications, Chronic kidney disease, Adverse drug events, Pharmaco-epidemiology, Older adults

\section{Background}

The prevalence of chronic kidney disease (CKD) is increasing, which affects aging populations especially [1]. CKD is associated with an increased risk of adverse drug events (ADE), particularly when older adults with multiple comorbidities are exposed to polypharmacy [2, 3]. Older adults are predisposed to develop acute kidney injury caused by dehydration or pre-existing kidney disease. Renal failure and aging process have an impact on pharmacokinetic and pharmacodynamic profiles of drugs and can result in an increased incidence of ADE [4]. Dose adjustments are therefore necessary for some drugs and their metabolites, which are excreted by the kidney in patients with CKD, to prevent potential ADE. In some cases, the treatment, e.g. metformin, has to be discontinued, if serious side effects occur [5].

The use of potentially inappropriate medication (PIM) can lead to adverse drug events (ADE) and is the cause of major health concern in older adults $[6,7]$. In Austria, a consensus-based list of potentially inappropriate drugs (AT-PIM list) serves as a source of information for healthcare professionals to limit ADE in the treatment of geriatric patients [8]. A widely accepted consensus list was developed in the US in 1991, which is known as "Beers-list" [9]. In 2015, in cooperation with experts from several countries, the EU(7)-PIM list was established, which contains 330 different substances $[9,10]$. The AT-PIM list [11] that contains 75 substances is based on the German PRISCUS list of PIM [12] and is customized to prescription practice in Austria.

The utilization of PIM assessed by claims data of certain health insurances varies across countries $[2,7$, 13-15]. Alarming is that in 2012 over 72\% of older adults in nursing homes in Austria received at least one PIM during observation period of 30 days [16]. This number is similar to a previous investigation in France [17]. Antidepressants, antipsychotics and nonsteroidal anti-inflammatory drugs (NSAIDs) have been reported to be the most prescribed substances in patients over 80 years in Austria [16]. Only few studies have investigated the prescription patterns of inappropriate medications in elderly patients with CKD $[1,18]$, the population of patients that is especially vulnerable and likely under high risk of ADE if PIM is prescribed. No study focused on PIM utilization neither estimated the risks of ADE due to PIM in older adults with CKD in Austria. The estimation of causal relationships in observational data has seen a lot of new developments in recent research, going far beyond simple descriptions and comparisons [19]. For example, marginal structural models (MSM) can provide estimates of causal effects of treatments that vary over time, but their application remains challenging with registry data [20]. In this study we have developed and applied the necessary methodology for estimating the risks of ADE after filling a PIM prescription using a large registry of prescriptions and hospitalizations.

The aims of this study were therefore defined as follows: 1) to estimate the utilization of PIM contained in EU(7)-PIM as well as AT-PIM lists in the population of older adults with CKD in Lower Austria, which is the country's largest and second most populous province; 2) to describe the risk of ADE within 30 days after a prescription of PIM was filled; 3) to apply MSM in order to attribute increased risk of $\mathrm{ADE}$ to filling a prescription of PIM relative to a PIM-free control group; 4) to investigate whether any other substances that are not included in the PIM lists increased the risk of ADE.

The paper is structured as follows: Methods section describes the methodology including study design and setting, the inclusion criteria defining the study population, outcomes and exposures of interest and statistical methods used for the analysis; subsequently, the results reporting the utilization of PIM and risk of ADE after a prescription of PIM or other medications are summarized; finally, our main findings together with strengths and limitations of the study are discussed.

\section{Methods}

\section{Study design, setting, sample size}

The health insurance is mandatory in Austria and healthcare is provided for all residents who are assigned membership in one of several health insurance funds depending on their current or former employment or province of residence. Data on medical services covered by the health insurance funds are collected in routine databases run by the Main Association of Austrian Social Insurance Institutions. For scientific purposes, data from the provincial health insurance fund of Lower Austria from 2008 to 2011 have been prepared in the database GAP-DRG2 [21]. Containing data from the 
second largest provincial sickness fund of Austria, GAPDRG2 covers approximately $14 \%$ of the population of Austria. About $71 \%$ of the Lower Austrian population is covered by this sickness fund. Only federal employees, farmers, independent entrepreneurs, and railway and mining employees are not covered.

The scientific database includes demographic data of the insured patients, their filled drug prescriptions, and, if applicable, any hospital discharge records containing date of discharge, length of stay, and primary and associated diagnoses coded using the 10th revision of the International Statistical Classification of Diseases and Related Health Problems (ICD10) system. Each medication is described by a unique Austrian pharmaceutical registration number linked to the Anatomical Therapeutic Chemical (ATC) Classification System, and for each prescription the ATC code, the volume and the specialty of prescriber (general practitioner or specialist) are recorded. We made use of these data to describe utilization of PIM in Austria and the risk of hospitalization due to ADE after a prescription of incident PIM in a retrospective cohort study. To correctly specify the temporal order of events, the study cohort was defined separately for each research aim. Analyses were carried out independently for each PIM from the EU(7)-PIM list and AT-PIM list, respectively. The study cohorts were selected by queries from the database applying the inclusion criteria detailed below. Reliability of the retrieved data was assessed by comparison of marginal frequencies with expectations from clinical expertise.

\section{Participants}

Patients aged 70 years or older who were discharged from a hospital with the principal or associate diagnosis of CKD were eligible for this study. CKD was defined based on ICD10 codes acute, chronic, and unspecified renal failure (N17, N18, and N19), including sub-codes. The following ATC codes and sub-codes of the substances, which are commonly prescribed to patients with CKD, were also used as an indication of CKD: drugs for treatment of hyperkalemia and hyperphosphatemia (V03AE), other antianemic preparations (B03XA), and $\mathrm{A} 11 \mathrm{C}$ vitamin $\mathrm{D}$ and analogues (including A11CC01, $\mathrm{A} 11 \mathrm{CC} 02, \mathrm{~A} 11 \mathrm{CC} 03, \mathrm{~A} 11 \mathrm{CC} 04, \mathrm{~A} 11 \mathrm{CC} 06, \mathrm{~A} 11 \mathrm{CC} 20$, A11CC55). In addition, to identify patients with CKD we followed the procedure developed based on diagnoses from hospitals and sick leaves to predict the ICD code from the ATC code [22]. Patients with a predicted probability of at least 0.9 of N17, N18 or N19 were also included in the study. In addition, an observational period of at least 90 days prior to PIM prescription needed to be available for each patient.

\section{Issue of interest}

Those (PIM) prescriptions were considered that were filled by a patient after a washout phase of at least 90 days during which the patient must not have filled a prescription for the same PIM. By this criterion we limited the investigation to $\mathrm{ADE}$ that occurred due to incident drug therapy but were more certainly related to one PIM as most of the studied patients were multimorbid and were filling many prescriptions simultaneously. The utilization of PIM contained in EU(7)-PIM as well as AT-PIM lists among older adults was described from several different aspects: as the proportion of filled prescriptions that contained a medication listed in the PIM lists, the proportion of patients that filled a prescription of a medication listed in PIM lists as well as the proportion of individual PIM prescribed out of all PIM contained in the lists. Frequencies of prescriptions of PIM were compared by specialty of prescriber (general practitioner or specialist).

\section{Endpoint}

ADE were defined based on 448 ICD10 codes (a list is contained in the supplement) and were not PIM specific. The ADE-relevant diagnoses were taken from Stausberg et al. who defined it for Germany [23], and adapted for studies exploring ADE in Austria [24, 25]. In addition, we considered only those ADE as relevant that occurred within 30 days after filling a prescription of any PIM.

\section{Comparison}

The MSM methodology demands that the treated and control groups are defined dynamically: at each specific time point and for each PIM the treated patients were those who filled a prescription for that PIM after fulfilling the inclusion criteria and the control group were all other patients who had by the time not (yet) filled a prescription for that PIM. Patients in the control group could later switch to the PIM group, if PIM was prescribed, and could switch back again to the control group if the 'washout' phase was completed and no new PIM was prescribed.

\section{Statistical analysis}

Continuous variables were described by median and interquartile range (IQR). Categorical data were described by absolute frequencies and percentages. The risk of ADE within the defined time horizon of 30 days after filling a prescription for a particular PIM was estimated as the proportion of patients with an occurrence of an ADE relative to the total number of patients receiving prescriptions for that PIM. Corresponding exact 95\% confidence intervals (CIs) were estimated by the Clopper-Pearson method. We considered a risk of $>1 \%$ 
as an indicator for clinically relevant increase in risk of ADE.

To compare the risk of ADE between patients who filled a particular PIM (PIM group) and the control group, MSM [26] were constructed for each PIM included in the EU(7)-PIM list and AT-PIM list, respectively. These comparisons were all adjusted for timedependent confounders where the dynamic covariates according to a patient's 90-days medical history (comorbidities defined as ICD10-chapters based on hospital discharge diagnoses (12 binary variables), co-medication defined as ATC 2nd levels based on filled prescriptions (96 binary variables), and total number of days of hospitalization) and demographic data (current age and sex) were considered. First, propensity scores (PS) were estimated as the predicted probabilities of filling a prescription for a PIM modeled by logistic regression of the PIM status (PIM or control) on all the covariates listed above, where the variables age and hospitalization days were modelled as restricted cubic spline functions with 4 knots. Second, from the propensity scores inverse probability weights (IPW) were computed as $1 / \mathrm{PS}$ and 1/(1-PS) for patients with PIM and controls, respectively. By inverse probability weighting, the two groups were made comparable as if they constituted a pseudopopulation which was randomized to PIM and control groups. The IPW were used to estimate weighted risks of ADE in both groups (PIM and control group) and the corresponding weighted relative risks and weighted risk differences. $p$-values for those quantities and standard errors for the computation of $95 \%$ CIs were obtained by blocked bootstrap, where patients were resampled 100times with replacement such that all observations of that patient were simultaneously included in a resample if that patient was sampled. More information on this methodology can be found in the work of Hernan et al. [26]. $p$-values were corrected for the multiplicity by controlling the false discovery rate at $10 \%$.

In addition to the analyses of substances listed as PIM in the EU(7)-PIM list and AT-PIM list respectively, we also screened other substances not included in the PIM lists for being potentially inappropriate for older CKD patients. By taking into account the 90-days washoutphase prior to a prescription, we first evaluated how often after filling a prescription for a substance an ADE followed within 30 days. Given the marginal incidences of ADE and prescriptions for that substance, we computed the expected distribution of such events under the null hypothesis that assumed no causal relationship between prescription and ADE. $p$-values were derived as the probabilities by which events were expected to randomly occur at least as often as observed. The p-values obtained were corrected for multiplicity by the procedure of Benjamini and Hochberg [27] which controls the false discovery rate. The number needed to harm, describing how many prescriptions were needed in order to expect one $\mathrm{ADE}$, was calculated as the ratio between the total number of filled prescriptions for a substance and the number of filled prescriptions after which an ADE occurred.

Statistical analysis was performed using $\mathrm{R}$ software (version: 3.6.1) [28].

\section{Sample size calculation}

Approximately 250,000 inhabitants of Lower Austria are of age 70 years or older [29]. Assuming a CKD prevalence of approximately $5 \%$ among them results in an estimated study population size of 12,500 people. If we assume a PIM utilization of $10 \%$, and ADE risks of 1.5 and $0.5 \%$ in the PIM and control groups, then the analysis has approximately $90 \%$ power to find a significantly increased ADE risk among PIM users at a significance level of $5 \%$. The expected width of a $95 \%$ confidence interval for the ADE risk among PIM users is 1.6 percentage points.

\section{Ethics}

Data were anonymised to preserve patients' privacy. Data storage and handling were in agreement with data protection laws. This study was supported by the Main Association of Austrian Social Insurance Institutions, approved by the Ethics Committee of the Medical University of Vienna (EK-No. 2278/2017) and performed in accordance with the Declaration of Helsinki. This was a retrospective study, therefore, informed consent was waived.

\section{Results}

\section{Study population}

We identified 11,547 patients who fulfilled the inclusion criteria and were eligible for the study. In 2008 patients were in median 78 (IQR: 73-83) years old, and 5845 (50.6\%) were female. In total, 40,999 hospitalizations were recorded for this study population between 2008 and 2011. In this period patients had a median of 2 (IQR: 1-5) hospitalizations with a median hospital stay duration of 5 (IQR: 2-11) days per hospitalization. 4950 (43\%) patients died during the follow-up between 2008 and 2011.

\section{Prescriptions of PIM}

This population of patients filled a total of 2,401,434 prescriptions during the follow-up period. 593,783 (24.7\%) and 193,809 (8.1\%) of the prescriptions contained a medication with a substance listed in the EU(7)- and AT-PIM list, respectively. The prescriptions for 157 (47.6\%) out of 330 different PIM included in the EU(7)-PIM list and for 65 (86.7\%) out 
of 75 different PIM in the AT-PIM list were filled by the patients during the follow-up. The ten most frequently prescribed PIM are listed in Table 1. 10,925 (94.6\%) and 9160 (79.3\%) patients received at least one EU(7)-PIM and AT-PIM prescription, respectively. In median one patient filled 60 (IQR: 33-94) prescriptions per year; of these 15 (IQR: 7-25) prescriptions per year were from the EU(7)-PIM and 6 (IQR: 2-12) from the AT-PIM list, respectively. General practitioners prescribed $90.4 \%$ of all filled prescriptions, and $92.2 \%$ of the recorded PIM.

\section{The risk of ADE after filling a prescription for PIM}

In the data we could identify only few ADE that occurred within 30 days after a patient had filled a prescription for PIM. Therefore, the risks of ADE were small and did not exceed 1\% for any of the filled PIM. For 7 PIM the upper confidence interval limit fell below $1 \%$, hence, no clinically important increase in risk after filling a prescription for these PIM could be detected. For other PIM the results were less clear due to too few filled prescriptions. These results are summarized in Table 2.

\section{The risk of ADE after filling a prescription for PIM as compared to the control group}

In the following analysis we considered the 46 PIM that were filled for a minimum of 100 times. The results presented as weighted relative risks and weighted risk differences adjusted for covariates are shown in Table 3 for the substances where significant effects by controlling the false discovery rate at $10 \%$ were detected. The risk of ADE after filling PIM prescription for 11 substances was significantly increased as compared to the control group. These substances were omeprazole, pantoprazole, lansoprazole, esomeprazole, metoclopramide, digitoxin, rilmenidine, spironolactone, tramadol, oxazepam, and theophylline. The risk was significantly reduced for the following 4 substances: metildigoxin, carbamazepine, diazepam, and amitriptyline.

\section{Explorative analysis of new PIM}

In addition to the analysis of substances that are already included in the PIM lists we also investigated whether any other substance increased the risk of ADE. An excerpt of these results is reported in Table 4. For clarity, we limit the findings only to substances where the strength of association resulted in an uncorrected $p$ value smaller than $10 \%$. Several antibiotic medicines, some pulmonary medicine and one anticoagulant showed a significant increase in risk of ADE. These associations were, however, not statistically significant after correcting for multiplicity (Table 4).

\section{Discussion}

In this retrospective epidemiological cohort study we estimated utilization statistics of PIM in patients with CKD aged 70 years or more and estimated the risk of

Table 1 Most frequently prescribed potentially inappropriate medication from the EU(7)-PIM and AT-PIM list (described by ATC code and name of the substance) together with the number of filled prescriptions between 2008 and 2011, patients' median (IQR) age at the time of filling the prescription and number (\%) of different patients filling the prescription

\begin{tabular}{|c|c|c|c|c|c|c|}
\hline ATC code & Substance & PIM list & $A D E$, increased risk of & Prescriptions, $\mathbf{n}$ & $\begin{array}{l}\text { Patients' age (years), } \\
\text { median (IQR) }\end{array}$ & Patients, n (\%) \\
\hline A02BC02 & Pantoprazole & $\mathrm{EU}(7)$ & $\begin{array}{l}\text { - C. difficile infection } \\
\text { - hip fracture }\end{array}$ & 107,233 & $79(74-84)$ & $6.947(60.2)$ \\
\hline A02BC03 & Lansoprazole & $\mathrm{EU}(7)$ & $\begin{array}{l}\text { - C. difficile infection } \\
\text { - hip fracture }\end{array}$ & 47,291 & $80(75-85)$ & $3.238(28.0)$ \\
\hline N06DX02 & Ginkgo biloba & $\mathrm{EU}(7), \mathrm{AT}$ & - orthostatic hypotension and fall & 31,395 & $81(77-86)$ & $2.266(19.6)$ \\
\hline $\mathrm{N} 02 \mathrm{AX} 02$ & Tramadol & $\mathrm{EU}(7), \mathrm{AT}$ & - CNS side effects & 28,130 & $78(74-84)$ & $4.115(35.6)$ \\
\hline M01AB05 & Diclofenac & $\mathrm{EU}(7), \mathrm{AT}$ & - Gl bleeding, ulceration, or perforation & 23,001 & $78(73-83)$ & $4.399(38.1)$ \\
\hline A02BC01 & Omeprazole & $\mathrm{EU}(7)$ & $\begin{array}{l}\text { - C. difficile infection } \\
\text { - hip fracture }\end{array}$ & 21,601 & $79(74-85)$ & $1.657(14.3)$ \\
\hline A02BC05 & Esomeprazole & $\mathrm{EU}(7)$ & $\begin{array}{l}\text { - C. difficile infection } \\
\text { - hip fracture }\end{array}$ & 20,821 & $79(74-84)$ & $1.682(14.6)$ \\
\hline C02CA04 & Doxazosin & $\mathrm{EU}(7)$ & $\begin{array}{l}\text { - orthostatic hypotension } \\
\text { - dry mouth } \\
\text { - urinary incontinence/ impaired micturition } \\
\text { - CNS side effects }\end{array}$ & 18,704 & $77(73-82)$ & $1.133(9.8)$ \\
\hline C04AD03 & Pentoxifyllin & $\mathrm{EU}(7), \mathrm{AT}$ & - orthostatic hypotension and fall & 12,658 & $80(76-85)$ & $1.065(9.2)$ \\
\hline C02AC06 & Rilmenidine & $\mathrm{EU}(7)$ & $\begin{array}{l}\text { - orthostatic hypotension } \\
\text { - bradycardia } \\
\text { - CNS side effects }\end{array}$ & 12,241 & $78(73-83)$ & $919(8.0)$ \\
\hline
\end{tabular}


Table 2 The risk of adverse drug events with 95\% confidence intervals (Cl) within 30 days after filling a prescription for potentially inappropriate medication (described by ATC code and name of the substance) listed in the EU(7)-PIM list or in the AT-PIM list along with observed frequencies of prescriptions and adverse drug events during the study period

\begin{tabular}{|c|c|c|c|c|c|c|}
\hline ATC code & Substance & $A D E$, increased risk of & PIM list & Prescriptions, $\mathrm{n}$ & $A D E, n$ & $\begin{array}{l}\text { Risk of ADE } \\
\%(95 \% \mathrm{Cl})\end{array}$ \\
\hline $\mathrm{A} 02 \mathrm{BC} 02$ & Pantoprazole & $\begin{array}{l}\text { - C. difficile infection } \\
\text { - hip fracture }\end{array}$ & $\mathrm{EU}(7)$ & 2162 & 4 & $0.19(0.05,0.47)$ \\
\hline M01AB05 & Diclofenac & - Gl bleeding, ulceration, or perforation & $\mathrm{EU}(7), \mathrm{AT}$ & 1908 & 3 & $0.16(0.03,0.46)$ \\
\hline N02AX02 & Tramadol & - CNS side effects & $\mathrm{EU}(7), \mathrm{AT}$ & 1300 & 3 & $0.23(0.05,0.67)$ \\
\hline C03DA01 & Spironolactone & $\begin{array}{l}\text { - hyperkalaemia } \\
\text { - hyponatremia }\end{array}$ & $\mathrm{EU}(7)$ & 871 & 2 & $0.23(0.03,0.83)$ \\
\hline M01AG01 & Mefenamic acid & - Gl bleeding, ulceration, or perforation & $\mathrm{EU}(7)$ & 757 & 4 & $0.53(0.14,1.35)$ \\
\hline N06DX02 & Ginkgo biloba & - orthostatic hypotension and fall & $\mathrm{EU}(7), \mathrm{AT}$ & 721 & 1 & $0.14(0.00,0.77)$ \\
\hline A03FA01 & Metoclopramid & $\begin{array}{l}\text { - may worsen peripheral arterial blood flow } \\
\text { and precipitate intermittent claudication }\end{array}$ & $\mathrm{EU}(7)$ & 634 & 1 & $0.16(0.00,0.88)$ \\
\hline A02BC03 & Lansoprazole & $\begin{array}{l}\text { - C. difficile infection } \\
\text { - hip fracture }\end{array}$ & $\mathrm{EU}(7)$ & 570 & 3 & $0.53(0.11,1.53)$ \\
\hline C01AA04 & Digitoxin & $\begin{array}{l}\text { - elevated glycoside sensitivity } \\
\text { - intoxication }\end{array}$ & $\mathrm{EU}(7)$ & 512 & 3 & $0.57(0.12,1.70)$ \\
\hline B01AA07 & Acenocoumarol & - bleeding & $\mathrm{EU}(7)$ & 480 & 1 & $0.21(0.01,1.16)$ \\
\hline C01BD01 & Amiodarone & $\begin{array}{l}\text { - QT interval problems } \\
\text { - torsades de pointes }\end{array}$ & $\mathrm{EU}(7)$ & 438 & 0 & $0.00(0.00,-0.84)$ \\
\hline C01AA08 & Metildigitoxin & $\begin{array}{l}\text { - elevated glycoside sensitivity } \\
\text { - intoxication }\end{array}$ & $\mathrm{EU}(7)$ & 382 & 1 & $0.26(0.01,1.45)$ \\
\hline G04BD09 & Trospium & - anticholinergic side effects & $\mathrm{EU}(7)$ & 366 & 0 & $0.00(0.00,1.00)$ \\
\hline N05CD05 & Triazolam & $\begin{array}{l}\text { - falls and hip fracture } \\
\text { - prolonged reaction time } \\
\text { - psychiatric reactions }\end{array}$ & $\mathrm{EU}(7), \mathrm{AT}$ & 329 & 1 & $0.30(0.01,1.68)$ \\
\hline N05BA12 & Alprazolam & $\begin{array}{l}\text { - falls and hip fracture } \\
\text { - prolonged reaction time } \\
\text { - psychiatric reactions }\end{array}$ & $\mathrm{EU}(7)$ & 289 & 0 & $0.00(0.00,1.27)$ \\
\hline N06AA09 & Amitriptyline & $\begin{array}{l}\text { - peripheral anticholinergic side effects } \\
\text { - central anticholinergic side effects } \\
\text { - cognitive deficit }\end{array}$ & $\mathrm{EU}(7), \mathrm{AT}$ & 280 & 0 & $0.00(0.00,1.31)$ \\
\hline R03DA04 & Theophylline & - CNS stimulant effects & $\mathrm{EU}(7), \mathrm{AT}$ & 275 & 0 & $0.00(0.00,1.33)$ \\
\hline A02BC05 & Esomeprazol & $\begin{array}{l}\text { - C. difficile infection } \\
\text { - hip fracture }\end{array}$ & $\mathrm{EU}(7)$ & 271 & 0 & $0.00(0.00,1.35)$ \\
\hline N05BA08 & Bromazepam & $\begin{array}{l}\text { - falls and hip fracture } \\
\text { - prolonged reaction time } \\
\text { - psychiatric reactions } \\
\text { - cognitive impairment } \\
\text { - depression }\end{array}$ & $\mathrm{EU}(7), \mathrm{AT}$ & 271 & 0 & $0.00(0.00,1.35)$ \\
\hline N05AX08 & Risperidone & $\begin{array}{l}\text { - behavioural symptoms of dementia } \\
\text {-increased mortality }\end{array}$ & AT & 252 & 0 & $0.00(0.00,1.45)$ \\
\hline C02CA04 & Doxazosin & $\begin{array}{l}\text { - orthostatic hypotension } \\
\text { - dry mouth } \\
\text { - urinary incontinence/ impaired micturition }\end{array}$ & $\mathrm{EU}(7)$ & 242 & 0 & $0.00(0.00,1.51)$ \\
\hline G03CA04 & Estriol & - carcinogenic potential & $\mathrm{EU}(7)$ & 232 & 1 & $0.43(0.01,2.38)$ \\
\hline $\mathrm{A} 02 \mathrm{BC} 01$ & Omeprazole & $\begin{array}{l}\text { - C. difficile infection } \\
\text { - hip fracture }\end{array}$ & $\mathrm{EU}(7)$ & 229 & 0 & $0.00(0.00,1.60)$ \\
\hline C04AD03 & Pentoxyfylline & - orthostatic hypotension and fall & $\mathrm{EU}(7), \mathrm{AT}$ & 208 & 0 & $0.00(0.00,1.76)$ \\
\hline
\end{tabular}

ATC code Anatomical Therapeutic Chemical Classification System, ADE Adverse drug event, CI Confidence interval

ADE after a prescription of PIM was filled. We observed that 65 of the $75(86.7 \%)$ medications that were suggested as potentially inappropriate for older adults in
Austria were prescribed to those patients. This number is substantially higher than reported results from a previous study conducted in geriatric patients in Austria [10], 
Table 3 Risk of ADE after filling a prescription for potentially inappropriate medication (described by ATC code and name of the substance) included in the EU(7)-PIM or AT-PIM list as compared to the control group described as relative risk and risk difference with 95\% confidence intervals (Cl), uncorrected $p$-values and $p$-values corrected for multiplicity by controlling the false discovery rate

\begin{tabular}{|c|c|c|c|c|c|c|}
\hline ATC code & Substance name & PIM list & Relative risk $(95 \% \mathrm{Cl})$ & Risk difference $(95 \% \mathrm{Cl})$ & $P$-value & Corrected $p$-value \\
\hline $\mathrm{A} 02 \mathrm{BC} 01$ & Omeprazole & $\mathrm{EU}(7)$ & $2.95(1.3,6.73)$ & $0.02(0.01,0.03)$ & 0.010 & 0.033 \\
\hline $\mathrm{A} 02 \mathrm{BC} 02$ & Pantoprazole & $\mathrm{EU}(7)$ & $3.71(1.37,10.05)$ & $0.03(0.02,0.03)$ & 0.010 & 0.033 \\
\hline $\mathrm{A} 02 \mathrm{BC} 03$ & Lansoprazole & $\mathrm{EU}(7)$ & $1.87(1.16,3.01)$ & $0.01(0,0.02)$ & 0.010 & 0.033 \\
\hline A02BC05 & Esomeprazole & $\mathrm{EU}(7)$ & $3.87(1.38,10.85)$ & $0.03(0.02,0.04)$ & 0.010 & 0.033 \\
\hline A03FA01 & Metoclopramide & $\mathrm{EU}(7)$ & $2.44(1.24,4.79)$ & $0.02(0.01,0.02)$ & 0.010 & 0.033 \\
\hline C01AA04 & Digitoxin & $\mathrm{EU}(7)$ & $1.89(1.17,3.06)$ & $0.01(0,0.02)$ & 0.010 & 0.033 \\
\hline C01AA08 & Metildigoxin & $\mathrm{EU}(7)$ & $0.37(0.17,0.79)$ & $-0.01(-0.01,0)$ & 0.010 & 0.033 \\
\hline C02AC06 & Rilmenidine & $\mathrm{EU}(7)$ & $2.35(1.09,5.09)$ & $0.01(0,0.03)$ & 0.030 & 0.094 \\
\hline C03DA01 & Spironolactone & $\mathrm{EU}(7)$ & $2.47(1.24,4.91)$ & $0.02(0.01,-0.02)$ & 0.010 & 0.033 \\
\hline N02AX02 & Tramadol & $\mathrm{EU}(7), \mathrm{AT}$ & $2.46(1.24,-4.89)$ & $0.02(0.01,0.02)$ & 0.010 & 0.033 \\
\hline N03AF01 & Carbamazepine & $\mathrm{EU}(7)$ & $0(0, \mathrm{NaN})$ & $-0.01(-0.01,-0.01)$ & 0.010 & 0.033 \\
\hline N05BA01 & Diazepam & $\mathrm{EU}(7), \mathrm{AT}$ & $0.4(0.2,0.8)$ & $-0.01(-0.01,0)$ & 0.010 & 0.033 \\
\hline N05BA04 & Oxazepam & $\mathrm{EU}(7), \mathrm{AT}$ & $2.85(1.11,7.33)$ & $0.02(0,0.04)$ & 0.030 & 0.094 \\
\hline N06AA09 & Amitriptyline & $\mathrm{EU}(7), \mathrm{AT}$ & $0.42(0.22,0.81)$ & $-0.01(-0.01,0)$ & 0.010 & 0.033 \\
\hline R03DA04 & Theophylline & $\mathrm{EU}(7), \mathrm{AT}$ & $2.32(1.22,-4.41)$ & $0.01(0.01,0.02)$ & 0.010 & 0.033 \\
\hline
\end{tabular}

ATC code Anatomical Therapeutic Chemical Classification System

and is comparable to the numbers reported in previous studies from Europe, Australia, and the US [13, 14, 30, 31]. A gender-specific difference in the prescription of PIM could not be detected in our study.

The utilization of PIM in Austria has been shifted from non-steroidal anti-inflammatory drugs, vasodilators and psychotropic drugs to proton pump inhibitors (PPI) and Ginkgo biloba [11]. In Italy, ketorolac, amiodarone, and clonidine were the most prescribed PIM [32]. In Sweden, PIMs such as NSAIDs, hypnotic and sedative drugs, and apixaban were commonly prescribed [33]. One should note that results from previous studies conducted worldwide vary due to the variations in methods, data collection, differently defined study population, and patient characteristics [34, 35].

The fact that PPI are frequently used by older adults should cause some concern. It has been shown that older adults suffer more often from falls, fractures, and from Clostridium difficile-associated diarrhea [36-38]. The higher risk of $\mathrm{ADE}$ as compared to the control group, such as bleeding, ulcer, intoxication, neurological and psychological symptoms, after PPI-intake reported in the present study is in line with results from previous studies [39-46]. Alarming is that approximately $40 \%$ of older patients with PPI had no indication for PPI use [47]. Since the utilization of PPI has increased worldwide the indication for the prescription of PPI should be strictly examined.

Another major concern is the prescription of Ginkgo biloba. Some positive impact on cognitive impairment and Alzheimer's disease is associated with its use, however, according to the EU(7)-PIM and AT-PIM list there is no efficacy proven for this herbal medicine. Moreover, it has been claimed that Ginkgo biloba is associated with increased risk of orthostatic hypotension and falls as well as increased cancer incidences for breast and colon [10, 48].

Our explorative analysis revealed several additional medications not yet included in the PIM lists that should be considered in the future research of PIM. Several antibiotics could be potentially harmful to geriatric patients with CKD. Although an increased risk of ADE could not be statistically confirmed after correcting for multiplicity, our results do not explicitly exclude this possibility because of an inflated type II error after multiplicity correction caused by rare occurrence of $\mathrm{ADE}$ and prescriptions for PIM. This is in accordance with results from a previous study that suggested vancomycin might cause nephropathy [49]. Fluconazole is prescribed for antifungal treatment of coccidioidomycosis, and it has already been reported that long-term use of fluconazole can lead to ADE in the population at risk [50]. Moreover, fluoroquinolone has been shown to cause ADE of central nervous system and tendinopathy in the older adults [51].

In the present study rilmenidine was found to cause an increased risk of ADE compared to the control group. This antihypertensive drug has been previously shown to be associated with an elevated risk for hospitalization and ADE in older adults [52]. In addition, patients receiving cardiovascular PIM such as doxazosin and rilmenidine, which had the highest prescribing frequency 
Table 4 Explorative analysis of (un)listed potentially inappropriate medication (described by ATC code and name of the substance) for older adults with chronic kidney disease. For each medication the total number of prescriptions and adverse drug events, a number needed to harm, an uncorrected $\mathrm{p}$-value and a p-value corrected for the multiplicity by controlling the false discovery rate are presented. Of these medication midazolam, ofloxacin and dabigatran etexilate are included in the EU(7)-PIM list

\begin{tabular}{|c|c|c|c|c|c|c|}
\hline ATC code & Substance name & Prescriptions, n & $A D E, n$ & $\mathrm{NNH}$ & $P$-value & Corrected $p$-value \\
\hline N05CD08 & Midazolam & 2 & 1 & 2 & $<0.001$ & 0.118 \\
\hline J01XA01 & Vancomycin & 5 & 1 & 5 & 0.001 & 0.450 \\
\hline C10AC01 & Cholestyramine & 65 & 3 & 21.7 & 0.004 & 0.749 \\
\hline J02AC01 & Fluconazole & 219 & 6 & 36.5 & 0.007 & 0.829 \\
\hline N05AL05 & Amisulpride & 47 & 2 & 23.5 & 0.012 & 0.892 \\
\hline N06AG02 & Moclobemide & 17 & 1 & 17 & 0.013 & 0.897 \\
\hline R05DB05 & Pentoxyverine & 21 & 1 & 21 & 0.019 & 0.929 \\
\hline M01AG & Fenamate & 24 & 1 & 24 & 0.024 & 0.943 \\
\hline V03AE03 & Lanthanum carbonate & 168 & 4 & 42 & 0.028 & 0.950 \\
\hline D01AC12 & Fenticonazole & 65 & 2 & 32.5 & 0.028 & 0.950 \\
\hline J01CF05 & Flucloxacillin & 27 & 1 & 27 & 0.030 & 0.954 \\
\hline J01CR04 & Sultamicillin & 181 & 4 & 45.3 & 0.036 & 0.961 \\
\hline J01EA01 & Trimethoprim & 747 & 12 & 62.3 & 0.040 & 0.965 \\
\hline L01AA01 & Cyclophosphamide & 32 & 1 & 32 & 0.041 & 0.966 \\
\hline D01AE22 & Naftifine & 76 & 2 & 38 & 0.041 & 0.966 \\
\hline D01AE15 & Terbinafine & 34 & 1 & 34 & 0.046 & 0.969 \\
\hline C09DX03 & $\begin{array}{l}\text { Olmesartan medoxomil, Amlodipine } \\
\text { and Hydrochlorothiazide }\end{array}$ & 36 & 1 & 36 & 0.051 & 0.972 \\
\hline P01AB01 & Metronidazole & 341 & 6 & 56.8 & 0.057 & 0.975 \\
\hline C05AX03 & Haemorrhoid treatment & 40 & 1 & 40 & 0.061 & 0.977 \\
\hline N02AA59 & Codeine & 41 & 1 & 41 & 0.064 & 0.978 \\
\hline J01MA01 & Ofloxacin & 301 & 5 & 60.2 & 0.083 & 0.983 \\
\hline B01AE07 & Dabigatran etexilate & 103 & 2 & 51.5 & 0.085 & 0.983 \\
\hline G01AX11 & Povidone-iodine & 50 & 1 & 50 & 0.089 & 0.984 \\
\hline R03BB01 & Ipratropium bromide & 110 & 2 & 55 & 0.098 & 0.985 \\
\hline
\end{tabular}

ATC code Anatomical Therapeutic Chemical Classification System, ADE Adverse drug event, NNH Number needed to harm

among cardiovascular PIM in the present study, have an increased risk of orthostatic hypotension [53, 54].

General practitioners were responsible for the majority of PIM prescriptions as they write most of all prescriptions in Austria. Patients usually receive their first prescription after being discharged from the hospital from their family doctor (general practitioner) or their specialist. The follow-up prescriptions are taken over by general practitioners.

The strengths of our study are well-defined inclusion criteria where only patients of at least 70 years with a chronic condition, i.e. CKD were selected. In such a population we can expect overall higher utilization of medication and possible changes in pharmacokinetics due to reduced kidney function causing accumulation of the drugs in the body that leads to likely toxicity and ADE. Furthermore, by using the scientific data base GAP-DRG2 that contains curated and cleaned data from a relatively large region of Lower Austria, which is Austria's second most populous province, structural distortion of the results due to self-selection bias or poor linkage and data quality could be avoided. Nonetheless, by appropriate adjustment for time-dependent confounding using state-of-the-art methodology for causal inference, we avoided bias in estimates of risks of ADE in patients receiving PIM relative to the control group.

Our study has several limitations. By using claims data from only one region of Austria and restricting the study cohort to CKD patients, only 11,547 individuals were eligible for the study, the number that is rather low for the investigation of extremely rare events such as ADE. Therefore, no definite results that would clearly indicate exceedance of the threshold level of $1 \%$ were obtained from the analysis of risks of ADE within 30 days after filling the prescription for PIM. Another possible explanation for small numbers of ADE is that ICD10 codes 
could underestimate the true numbers. Also many minor ADE may have been handled in an outpatient setting and thus excluded from analyses. Moreover, while ICD10 codes of hospital discharge diagnosis were used to identify CKD patients, neither clinical diagnosis nor case severity was adjudicated for in the analysis. There also remains a possibility of information bias regarding the diagnoses registered for hospitalizations defining ADE. The patients that were eligible for the study were multimorbid and had a high risk of being exposed to polypharmacy. Therefore, to relate ADE to a particular PIM with a greater certainty, a criterion was set by which the investigation was limited to ADE that occurred due to incident drug therapy only, disregarding the chance that some ADE might have also occurred as a cause of prevalent drug therapy. With this strict criterion we could attribute ADE to newly prescribed PIM very specifically and avoiding false positive attributions but at the cost of probably even underestimating the ADE risk after PIM use. Information of prescribed medication was limited to those medicines which were reimbursed by health care providers, and over-the-counter medication was not included in our analysis. Nonetheless, we were not able to assess actual adherence to medication for which prescriptions had been filled. Lastly, by making use of a curated scientific database we had to compromise on the recency of the data. There is a risk that utilization may have changed within the last few years, and this may affect our estimated absolute risks and risk differences, but estimated relative risks, which are independent of the level of utilization of a PIM, are robust to potential trends in utilization.

\section{Conclusion}

The awareness of PIM leading to ADE might be increased by PIM lists, however, drugs assigned as potentially inappropriate are not necessarily contraindicated. A population-wide study should be planned to record the usage of PIM among older adults in Austria and its consequences, e.g. the occurrence of ADE. Many substances are listed in both the EU(7)-PIM and the ATPIM list, but only a small number of drugs could be linked to serious clinically relevant ADE due to incident therapy. To facilitate treatment of older adults that are often multimorbid, it is therefore advisable to consider adapting the AT-PIM list by adding the assessments of ADE severity by using a warning system similar to a traffic light system based on their severity score.

\section{Supplementary Information}

The online version contains supplementary material available at https://doi. org/10.1186/s12877-021-02057-5.

Additional file 1. List of adverse drug events.

\section{Abbreviations}

ADE: Adverse drug events; ATC code: Anatomical Therapeutic Chemical Classification System; Cl: Confidence intervals; CKD: Chronic kidney disease; ICD10: The 10th revision of the International Statistical Classification of Diseases and Related Health Problems; IPW: Inverse probability weights; IQR: Interquartile range; MSM: Marginal structural models; NSAI

D: Nonsteroidal anti-inflammatory drugs; PIM: Potentially inappropriate medication; PPI: Proton pump inhibitors; PS: Propensity score

\section{Acknowledgements}

We want to thank the Main Association of Austrian Social Security Institutions and especially Gottfried Endel for granting us access to their database. Furthermore, we thank Andrea Haberson for the initial data preparation and analysis.

\section{Authors' contributions}

Conceptualization: W.G., G.H. and M.W. Methodology: G.H. and H.S. Formal analysis and investigation: C.R., A.S. and H.Š. Writing - original draft preparation: S.S.R. and H.S. Writing - review and editing: all authors. All authors have read and approved the submitted version.

\section{Funding}

This study was partly financially supported by the Main Association of Austrian Social Security Institutions that also collected the data. The funders had no role in the study design, analysis, interpretation of the results nor in writing the manuscript.

\section{Availability of data and materials}

The data that support the findings of this study are available from the Main Association of Austrian Social Security Institutions but restrictions apply to the availability of these data, which were used under license for the current study, and so are not publicly available. Data are however available from the authors upon reasonable request and with permission of the Main

Association of Austrian Social Security Institutions.

\section{Ethics approval and consent to participate}

This retrospective study was approved by the Ethics Committee of the Medical University of Vienna (EK-No. 2278/2017) and individual informed consent was waived.

\section{Consent for publication}

Not applicable.

\section{Competing interests}

Walter Gall has received a research grant from the Main Association of Austrian Social Security Institutions. All other authors declare no competing interests.

\section{Author details}

${ }^{1}$ Department of Clinical Pharmacology, Medical University of Vienna, Spitalgasse 23, 1090 Vienna, Austria. 'Section for Clinical Biometrics, Center for Medical Statistics, Informatics and Intelligent Systems, Medical University of Vienna, Spitalgasse 23, 1090 Vienna, Austria. ${ }^{3}$ Section for Medical Information Management, Center for Medical Statistics, Informatics and Intelligent Systems, Medical University of Vienna, Spitalgasse 23, 1090 Vienna, Austria.

Received: 8 October 2020 Accepted: 31 January 2021

Published online: 10 February 2021

\section{References}

1. Breton G, Froissart M, Janus N, Launay-Vacher V, Berr C, Tzourio C, Helmer C, Stengel B. Inappropriate drug use and mortality in community-dwelling elderly with impaired kidney function--the Three-City population-based study. Nephrol Dial Transplant. 2011;26(9):2852-9.

2. Tesfaye $\mathrm{WH}$, Wimmer BC, Peterson GM, Castelino RL, Jose MD, McKercher C, Zaidi STR. The effect of hospitalization on potentially inappropriate medication use in older adults with chronic kidney disease. Curr Med Res Opin. 2019;35(6):1119-26. 
3. Secora A, Alexander GC, Ballew SH, Coresh J, Grams ME. Kidney function, polypharmacy, and potentially inappropriate medication use in a community-based cohort of older adults. Drugs Aging. 2018;35(8):735-50.

4. Qato DM, Alexander GC, Conti RM, Johnson M, Schumm P, Lindau ST. Use of prescription and over-the-counter medications and dietary supplements among older adults in the United States. JAMA. 2008; 300(24):2867-78.

5. Verbeeck RK, Musuamba FT. Pharmacokinetics and dosage adjustment in patients with renal dysfunction. Eur J Clin Pharmacol. 2009;65(8):757-73.

6. Hanlon JT, Schmader KE, Ruby CM, Weinberger M. Suboptimal prescribing in older inpatients and outpatients. J Am Geriatr Soc. 2001;49(2):200-9.

7. Fick DM, Mion LC, Beers MH, Waller JL. Health outcomes associated with potentially inappropriate medication use in older adults. Res Nurs Health. 2008;31(1):42-51.

8. Österreichs ÖG. Österreichische PIM-Liste; 2012.

9. Beers MH, Ouslander JG, Rollingher I, Reuben DB, Brooks J, Beck JC. Explicit criteria for determining inappropriate medication use in nursing home residents. Arch Intern Med. 1991;151(9):1825-32.

10. Renom-Guiteras A, Meyer G, Thürmann PA. The EU(7)-PIM list: a list of potentially inappropriate medications for older people consented by experts from seven European countries. Eur J Clin Pharmacol. 2015;71(7): $861-75$

11. Mann E, Böhmdorfer B, Frühwald T, Roller-Wirnsberger RE, Dovjak $P$, Dückelmann-Hofer C, Fischer P, Rabady S, Iglseder B. Potentially inappropriate medication in geriatric patients: the Austrian consensus panel list. Wien Klin Wochenschr. 2012;124(5):160-9.

12. Holt S, Schmiedl S, Thürmann PA. Potenziell inadäquate Medikation für ältere Menschen. Dtsch Arztebl Int. 2010;107(31-32):543-51.

13. Reich O, Rosemann T, Rapold R, Blozik E, Senn O. Potentially inappropriate medication use in older patients in Swiss managed care plans: prevalence, determinants and association with hospitalization. PLoS One. 2014;9(8): e105425.

14. Gallagher $P$, Lang PO, Cherubini A, Topinková E, Cruz-Jentoft A, Montero Errasquín B, Mádlová P, Gasperini B, Baeyens H, Baeyens J-P, et al. Prevalence of potentially inappropriate prescribing in an acutely ill population of older patients admitted to six European hospitals. Eur J Clin Pharmacol. 2011;67(11):1175.

15. Morin L, Fastbom J, Laroche M-L, Johnell K. Potentially inappropriate drug use in older people: a nationwide comparison of different explicit criteria for population-based estimates. Br J Clin Pharmacol. 2015;80(2):315-24.

16. Alzner R, Bauer U, Pitzer S, Schreier MM, Osterbrink J, Iglseder B. Polypharmacy, potentially inappropriate medication and cognitive status in Austrian nursing home residents: results from the OSiA study. Wien Med Wochenschr. 2016;166(5):161-5.

17. Cool C, Cestac P, Laborde C, Lebaudy C, Rouch L, Lepage B, Vellas B, Barreto PS, Rolland $Y$, Lapeyre-Mestre M. Potentially inappropriate drug prescribing and associated factors in nursing homes. J Am Med Dir Assoc. 2014;15(11): 850.e851-9.

18. Quintana-Bárcena P, Lord A, Lizotte A, Berbiche D, Lalonde L. Prevalence and management of drug-related problems in chronic kidney disease patients by severity level: a subanalysis of a cluster randomized controlled trial in community pharmacies. J Manag Care Spec Pharm. 2018;24(2):173-81.

19. Hernán MA, Hsu J, Healy B. A second chance to get causal inference right: a classification of data science tasks. Chance. 2019;32(1):42-9.

20. Heinze G, Wallisch C, Kainz A, Hronsky M, Leffondré K, Oberbauer R, Mayer $\mathrm{G}$. Chances and challenges of using routine data collections for renal health care research. Nephrol Dial Transplant. 2015;30(Suppl 4):iv68-75.

21. Glock B, Endel F, Endel G, Popper N. Challenges and results with the record linkage of Austrian health insurance data of different sources. Abstract no. 495. In: Scott PJ, Cornet R, McCowan C, et al, editors. Informatics for Health: Advancing both science and practice. BMJ Health \& Care Informatics; 2017. p. 24.

22. Eisl A, Mert C, Filzmoser P. ATC-ICD10 evaluation. Final report; 2014.

23. Stausberg J, Hasford J. Identification of adverse drug events. Dtsch Arztebl Int. 2010;107(3):23-9.

24. Gall W, Endel G, Grossmann W, Jankowitsch-Zimbova S, Ratajczak P, Sheikh Rezaei S, Rinner C, Wolzt M. Adverse drug events in Austrian hospital discharge diagnoses, Health - Exploring Complexity: an interdisciplinary systems approach (HEC2016). Eur J Epidemiol. 2016;31:61.

25. Gall W, Neuhofer L, Rinner C, Endel G, Grossmann W, Marzluf B, Wolzt M. Relationship of drug-drug interactions with hospital diagnoses associated to adverse drug reactions. Int J Clin Pharmacol Toxicol. 2015; S1(001):1-6.

26. Hernán MÁ, Brumback B, Robins JM. Marginal structural models to estimate the causal effect of Zidovudine on the survival of HIV-positive men. Epidemiology. 2000;11(5):561-70.

27. Benjamini $Y$, Hochberg $Y$. Controlling the false discovery rate: a practical and powerful approach to multiple testing. J R Stat Soc Ser B Methodol. 1995;57(1):289-300.

28. Team RC. R: a language and environment for statistical computing. Vienna: R foundation for Statistical Computing; 2017.

29. Statistics Austria. 2017. https://www.statistik.at/web_en/statistics/index.html. Accessed 15 Dec 2017

30. García-Gollarte F, Baleriola-Júlvez J, Ferrero-López I, Cruz-Jentoft AJ. Inappropriate drug prescription at nursing home admission. J Am Med Dir Assoc. 2012;13(1):83.e89-15.

31. Fialová D, Topinková E, Gambassi G, Finne-Soveri H, Jónsson PV, Carpenter I, Schroll M, Onder G, Sørbye LW, Wagner C, et al. Potentially inappropriate medication use among elderly home care patients in Europe. JAMA. 2005; 293(11):1348-58.

32. Napolitano F, Izzo M, Di Giuseppe G, Angelillo I, Group tCW, Group CW. Frequency of inappropriate medication prescription in hospitalized elderly patients in Italy. PLoS One. 2013;6(12):e82359.

33. Wamil N, Mattsson S, Gustafsson M. Assessment of potentially inappropriate medications using the EU (7)-PIM list and the Swedish quality indicators. Int J Clin Pharm. 2019;41(4):903-12.

34. Alhawassi TM, Alatawi W, Alwhaibi M. Prevalence of potentially inappropriate medications use among older adults and risk factors using the 2015 American Geriatrics Society Beers criteria. BMC Geriatr. 2019;19(1):154.

35. Wang T-C, Ku P-J, Lu H-L, Hsu K-C, Trezise D, Wang H-Y. Association between potentially inappropriate medication use and chronic diseases in the elderly. Int J Environ Res Public Health. 2019;16(12):2189.

36. Bor A, Matuz M, Csatordai M, Szalai G, Bálint A, Benkő R, Soós G, Doró P. Medication use and risk of falls among nursing home residents: a retrospective cohort study. Int J Clin Pharm. 2017;39(2):408-15.

37. Janarthanan S, Ditah I, Adler DG, Ehrinpreis MN. Clostridium difficileassociated diarrhea and proton pump inhibitor therapy: a meta-analysis. Am J Gastroenterol. 2012;107(7):1001-10.

38. Thaler HW, Sterke CS, Van Der Cammen TJM. Association of proton pump inhibitor use with recurrent falls and risk of fractures in older women: a study of medication use in older fallers. J Nutr Health Aging. 2016;20(1):77-81.

39. Cea-Soriano L, Johansson S, García Rodríguez LA. Risk factors for falls with use of acid-suppressive drugs. Epidemiology. 2013;24(4):600-7.

40. Chiu H-F, Huang $\mathrm{Y}-\mathrm{W}$, Chang $\mathrm{C}-\mathrm{C}$, Yang $\mathrm{C}-\mathrm{Y}$. Use of proton pump inhibitors increased the risk of hip fracture: a population-based case-control study. Pharmacoepidemiol Drug Saf. 2010;19(11):1131-6.

41. Dial S, Alrasadi K, Manoukian C, Huang A, Menzies D. Risk of Clostridium difficile diarrhea among hospital inpatients prescribed proton pump inhibitors: cohort and case-control studies. Can Med Assoc J. 2004;171(1):33-8.

42. Dial S, Delaney JAC, Barkun AN, Suissa S. Use of gastric acid-suppressive agents and the risk of community-acquired Clostridium difficile-associated disease. JAMA. 2005;294(23):2989-95.

43. Maes ML, Fixen DR, Linnebur SA. Adverse effects of proton-pump inhibitor use in older adults: a review of the evidence. Ther Adv Drug Saf. 2017;8(9):273-97.

44. Ngamruengphong S, Leontiadis Gl, Radhi S, Dentino A, Nugent K. Proton pump inhibitors and risk of fracture: a systematic review and meta-analysis of observational studies. Am J Gastroenterol. 2011;106(7):1209-18.

45. Pouwels $S$, Lalmohamed A, Souverein P, Cooper C, Veldt BJ, Leufkens HG, de Boer A, van Staa T, de Vries F. Use of proton pump inhibitors and risk of hip/femur fracture: a population-based case-control study. Osteoporos Int. 2011;22(3):903-10.

46. Sarkar $M$, Hennessy $S$, Yang Y. Proton-pump inhibitor use and the risk for community-acquired pneumonia. Ann Intern Med. 2008;149(6):391-8.

47. Wallerstedt SM, Fastbom J, Linke J, Vitols S. Long-term use of proton pump inhibitors and prevalence of disease- and drug-related reasons for gastroprotection-a cross-sectional population-based study. Pharmacoepidemiol Drug Saf. 2017;26(1):9-16.

48. Biggs ML, Sorkin BC, Nahin RL, Kuller LH, Fitzpatrick AL. Ginkgo biloba and risk of cancer: secondary analysis of the Ginkgo evaluation of memory (GEM) study. Pharmacoepidemiol Drug Saf. 2010;19(7):694-8. 
49. Luque $Y$, Louis K, Jouanneau C, Placier S, Esteve E, Bazin D, Rondeau E, Letavernier E, Wolfromm A, Gosset C, et al. Vancomycin-associated cast nephropathy. J Am Soc Nephrol. 2017;28(6):1723-8.

50. Davis MR, Nguyen M-VH, Donnelley MA, Thompson GR III. Tolerability of long-term fluconazole therapy. J Antimicrob Chemother. 2018;74(3):768-71.

51. Haiping L, Ziqiang J, Qina Z, Yuhua D. Adverse reactions of

fluoroquinolones to central nervous system and rational drug use in nursing care. Pak J Pharm Sci. 2019;32(1(Special)):427-32.

52. Hines LE, Murphy JE. Potentially harmful drug-drug interactions in the elderly: a review. Am J Geriatr Pharmacother. 2011;9(6):364-77.

53. Langdon CG, Packard RS. Doxazosin in hypertension: results of a general practice study in 4809 patients. Br J Clin Pract. 1994;48(6):293-8.

54. Pelemans W, Verhaeghe J, Creytens G, Coupez G, Van Dessel A, Opsomer M. Efficacy and safety of rilmenidine in elderly patients_comparison with hydrochlorothiazide. Am J Cardiol. 1994;74(13):A51-7.

\section{Publisher's Note}

Springer Nature remains neutral with regard to jurisdictional claims in published maps and institutional affiliations.

Ready to submit your research? Choose BMC and benefit from:

- fast, convenient online submission

- thorough peer review by experienced researchers in your field

- rapid publication on acceptance

- support for research data, including large and complex data types

- gold Open Access which fosters wider collaboration and increased citations

- maximum visibility for your research: over $100 \mathrm{M}$ website views per year

At BMC, research is always in progress.

Learn more biomedcentral.com/submissions 